\title{
Telemedicine for Retinopathy of Prematurity Diagnosis:
}

\section{Evaluation and Challenges}

Grace M. Richter, MD ${ }^{1,2}$, Steven L. Williams, MD ${ }^{1}$, Justin Starren, MD, PhD ${ }^{3,4}$, John T. Flynn, $M^{1}$, and Michael F. Chiang, MD ${ }^{1,4}$

${ }^{1}$ Department of Ophthalmology, Columbia University College of Physicians and Surgeons, New York, NY

${ }^{2}$ Columbia University Mailman School of Public Health, New York, NY

${ }^{3}$ Biomedical Informatics Research Center, Marshfield Clinic, Marshfield, WI

${ }^{4}$ Department of Biomedical Informatics, Columbia University College of Physicians and Surgeons, New York, NY

\section{Abstract}

Retinopathy of prematurity (ROP) is a vasoproliferative disorder affecting low birth weight infants. Although timely diagnosis and treatment can significantly reduce the risk of severe complications, ROP remains a leading cause of childhood blindness worldwide. Limitations of current disease management strategies include extensive travel and logistical coordination requirements for ophthalmologists and neonatologists, decreasing availability of adequately-trained ophthalmologists at the point of care, variability in how retinal findings are diagnosed and documented, and a growing need for ROP care worldwide. Store-and-forward telemedicine is an emerging technology by which medical data are captured for subsequent interpretation by a remote expert. This has potential to improve accessibility, quality, and cost of ROP management. In this paper, we summarize the current evaluation data on applications of telemedicine for ROP, particularly involving the diagnostic accuracy and reliability of remote image interpretation by experts. We also address challenges such as the cost-effectiveness of telemedicine, and highlight potential barriers to implementation of these systems. Understanding these principles is essential to determine future directions in research and development of telemedicine systems for ROP, as well as for other ophthalmic diseases.

\section{Keywords}

retinopathy of prematurity; telemedicine; diagnostic imaging; medical informatics; retina; diagnostic techniques and procedures; blindness

(C) 2009 Elsevier Inc. All rights reserved.

Correspondence to: Michael F. Chiang, MD, Herbert Irving Assistant Professor of Ophthalmology and Biomedical Informatics, Columbia University College of Physicians and Surgeons, 635 West $165^{\text {th }}$ Street, Box 92, New York, NY 10032, Tel: 212-342-3440 | Fax: 212-305-5962 | chiang@dbmi.columbia.edu.

Publisher's Disclaimer: This is a PDF file of an unedited manuscript that has been accepted for publication. As a service to our customers we are providing this early version of the manuscript. The manuscript will undergo copyediting, typesetting, and review of the resulting proof before it is published in its final citable form. Please note that during the production process errors may be discovered which could affect the content, and all legal disclaimers that apply to the journal pertain. 


\section{Retinopathy of Prematurity}

\section{A. Introduction and Epidemiology}

Retinopathy of prematurity (ROP) is a vasoproliferative retinal disorder affecting low birth weight infants. Treatment criteria for severe disease, using laser photocoagulation and cryotherapy, have been established through the Cryotherapy for Retinopathy of Prematurity (CRYO-ROP) and Early Treatment for Retinopathy of Prematurity (ETROP) trials. ${ }^{18,22,29,}$ ${ }^{56}$ Nonetheless, of the approximately 4 million infants born each year in the United States, roughly 2,100 premature babies are affected by long-term sequelae of ROP such as strabismus, myopia, and retinal detachment. ${ }^{50,57}$ Among these infants, 400-900 develop ROP-related blindness annually. ${ }^{57}$

Management of ROP has been supported by universal, evidence-based standards. In particular, research on the natural progression of disease has led to strategies for diagnosis and classification. ${ }^{55,56}$ Development of an international classification system has standardized reporting of the severity, extent, and location of retinal abnormalities in ROP. ${ }^{17,36}$ Policy statements for examination of at-risk infants have been published jointly by the American Academy of Ophthalmology, American Academy of Pediatrics, and American Association for Pediatric Ophthalmology and Strabismus. ${ }^{64,65}$ These statements recommend that at-risk infants with birth weight (BW) $<1500$ grams or gestational age $\leq 30$ weeks, and infants with BW 1500-2000 grams or gestational age $>30$ weeks with an unstable clinical course, should receive dilated ophthalmoscopic examinations.

ROP remains a leading cause of treatable childhood blindness in the United States and throughout the world. In developed countries, the number of infants at risk for ROP has been increasing. This is in part because of higher premature birth rates due to reasons such as assisted conception, increasing maternal age, possible genetic etiologies, and other socioeconomic issues. ${ }^{16,67}$ In the United States, the rate of prematurity has risen from $9.4 \%$ of all births in 1981 to $12.7 \%$ in $2005.33,50$ In regions such as Latin America, Eastern Europe, and Asia, the number of ROP cases has grown dramatically because of higher overall birth rates, as well as improved neonatal survival from greater availability of neonatal care. ${ }^{27,28}$ Concerns have been raised about an emerging international ROP "epidemic" due to a shortage of adequately trained ophthalmologists and persistent variability in quality of neonatal care. ${ }^{8,26,28,72}$ There is also evidence that larger infants may develop ROP in some regions, highlighting the need for regionspecific ROP management guidelines. ${ }^{9,26,27,72}$

\section{B. Limitations of Current Care Strategies}

From the standpoint of physicians who manage ROP, there are many logistical challenges to providing optimal care. Examinations require specialized training and are typically performed by retinal specialists or pediatric ophthalmologists, who may not be readily available in rural and other areas. Infants typically receive multiple examinations at regular intervals, requiring coordination of care between ophthalmologists and neonatal intensive care unit (NICU) staff. Moreover, the precise documentation of examination findings, which traditionally relies on hand-drawn pictures with annotation of zone, stage, extent, and presence of plus disease, is somewhat subjective and may be a source of medico-legal liability. There also may be a growing shortage of physicians who manage ROP. A 2006 American Academy of Ophthalmology survey found that only $54 \%$ of retinal specialists and pediatric ophthalmologists are willing to manage ROP, and that over $20 \%$ plan to stop because of concerns such as poor reimbursement, logistical difficulty, and medico-legal liability. (American Academy of Ophthalmology. Ophthalmologists warn of shortage in specialists who treat premature babies with blinding eye condition. 
http://www.aao.org/newsroom/release/20060713.cfm. Accessed May 6, 2008.) New strategies, such as telemedicine, may be helpful in addressing these problems.

\section{Telemedicine}

\section{A. General Principles}

Telemedicine is defined as the use of information technologies to support health care between participants who are separated from each other. ${ }^{24}$ It has potential to improve the accessibility, quality, and cost of healthcare, and may also contribute to medical education and research. These consultations can be divided into two categories: synchronous telemedicine utilizes telecommunications for real-time interactions between participants (e.g., video conferencing), whereas store-and-forward telemedicine involves the capture of patient data for subsequent interpretation by a remote expert (e.g., digital radiology). Telemedicine programs emerged in the United States over 40 years ago with mixed success. Since that time, major telemedicine projects have been discontinued after their initial period of funding due to technological limitations and lack of financial sustainability. ${ }^{5,24}$ Advances in information technology, along with growing concerns about rising costs and inequities in healthcare accessibility, have revived interest in telemedicine. In particular, large-scale store-and-forward applications have been implemented in specialties such as radiology and pathology, which rely heavily on the interpretation of data from image-based modalities. ${ }^{32,44}$

\section{B. Applications to ROP}

Telemedicine has the potential to address some of the challenges associated with current ROP management and quality of care. In store-and-forward telemedicine programs for ROP, images would likely be captured by trained neonatal personnel for subsequent grading by a remote ophthalmologist. This could improve travel time for ophthalmologists, logistical coordination with neonatal staff, and accessibility to expert care for patients. Serial retinal imaging may offer a more objective method for documentation of disease findings and progression. In addition, widespread retinal imaging for ROP would provide opportunities to create digital libraries for educational and research purposes. This could potentially improve the uniformity of ROP diagnosis. Retinal photography might also cause less physiologic stress to infants than ophthalmoscopy with scleral depression. ${ }^{51,52}$ Of note, digital retinal imaging has been successfully utilized in other pediatric retinal conditions such as retinoblastoma and shaken baby syndrome. ${ }^{35,48}$

\section{Feasibility and Evaluation Studies}

\section{A. Study Design Considerations}

Several studies have examined the application of telemedicine for ROP diagnosis (Tables 1, 2 and 3). In general, these studies have compared performance of image-based diagnosis by remote experts to a reference standard of dilated examination by an ophthalmologist. Recognizing key differences in experimental design is necessary to compare these studies.

First, imaging methods have differed based on: 1) Type of device used. This has included wideangle contact cameras $4,13-15,23,46,59,62-63,66,76,77$ (RetCam; Clarity Medical Systems, Pleasanton, CA) as well as narrow-angle non-contact cameras ${ }^{69}$ (Nidek NM200-D, Hiroishi, Japan). 2) Number of images captured from each eye. 3) Expertise of the camera operator. This has included trained neonatal nurses, ${ }^{15,46,59,63,69,77}$ ophthalmic photographers, ${ }^{13,14,59,76}$ and ophthalmologists. ${ }^{4,23,62,66,76}$

Second, conditions for telemedical image grading have varied based on: 1) Expertise of graders. These have included general ophthalmologists, ${ }^{13}$ as well as retinal specialists and pediatric 


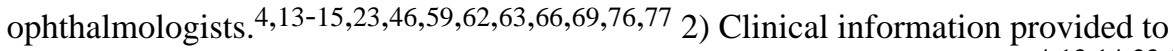
telemedical graders. Some studies have apparently displayed only images, 4,13,14,23,59,66,69, 77 whereas others have provided additional data such as demographics and clinical history. $15,46,62,63,763)$ Presentation of images. Some studies have displayed them one eye at a time, $4,13,14,23,59,66$ while others have shown them both eyes at a time $15,46,62,63,69$ to simulate realworld clinical situations.

Third, study populations have varied from a selection of ROP cases ${ }^{62}$ to consecutivelyrecruited infants in real-world NICU populations. ${ }^{4,13-15,23,46,59,63,66,69,76,77}$ Fourth, outcome measures have differed based on the diagnostic cut-off. This has included detection of any

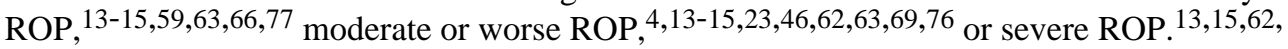
63 Finally, some studies have examined telemedicine performance at individual examinations, $13-15,46,59,62,63,76,77$ whereas others have analyzed performance over multiple longitudinal examinations. ${ }^{4,23,69}$

\section{B. Accuracy}

1. Accuracy of Diagnosing Any ROP-Several studies have evaluated telemedicine for the detection of mild or worse ROP using multiple wide-angle retinal images (RetCam-120 or RetCam-II; Clarity Medical Systems, Pleasanton, CA), compared to a reference standard of dilated ophthalmoscopy by an expert (Table 1). Roth et al. (2001; 100 exams from 32 infants), found sensitivity of 0.82 and a specificity of $0.94 .{ }^{59}$ Shah et al. (2006; 87 exams from 27 infants) reported similar findings, with sensitivity of 0.86 and a specificity of $0.92 .{ }^{66}$ Chiang et al. (2006; 163 exams from 64 infants) evaluated telemedicine for detection of any ROP by 3 image graders (one general ophthalmologist and two retinal specialists), and demonstrated a range in sensitivity of $0.82-0.86$ and specificity of $0.49-0.96 .{ }^{13}$ When data from the general ophthalmologist were excluded, the range of sensitivity and specificity was $0.82-0.85$ and 0.91-0.96, respectively. ${ }^{13}$ These studies attributed lower sensitivity to missed cases of mild peripheral ROP that were not captured during retinal imaging. ${ }^{13,59,66}$

Yen et al. (2002; 82 exams from 25 infants) demonstrated a higher accuracy for detection of any ROP in infants at later post-menstrual ages (PMA). For infants at 32-34 weeks PMA, sensitivity was 0.47 and specificity was 1.00 . For infants at 38-40 weeks PMA, sensitivity was 0.76 and specificity was $1.00 .^{77}$ This tendency toward higher accuracy at later PMA was also demonstrated prospectively by Chiang et al. (2007; 248 exams from 68 infants), who evaluated accuracy of 3 pediatric retinal specialists. Sensitivity improved from 0.73-0.94 (at 31-33 weeks PMA) to 0.91-0.97 (at 35-37 weeks PMA), and specificity improved from 0.89-0.97 (at 31-33 weeks PMA) to 0.98-1.00 (at 35-37 weeks PMA). ${ }^{15}$ Higher accuracy at later PMAs has been attributed to improved image quality and capture because of larger palpebral fissures, larger eyes, and less corneal and vitreous haze. ${ }^{15,76,77}$

2. Accuracy of Diagnosing Moderate to Severe ROP-Other studies have examined the accuracy of telemedicine for diagnosing moderate to severe ROP using multiple wide-angle images (Table 2). In a group of pre-selected cases with relatively severe ROP, Schwartz et al. (2000; 19 exams from 10 infants) reported that 18/19 (95\%) eyes showed agreement between telemedicine and ophthalmoscopy for plus disease diagnosis and 17/19 (89\%) eyes showed agreement between telemedicine and ophthalmoscopy for presence of prethreshold or worse ROP. 62

Three studies have examined cohorts of consecutively-enrolled infants in real-world NICU situations, and compared telemedicine interpretation to a reference standard of dilated ophthalmoscopy at the time of each individual examination. Wu et al. (2006; 86 exams from 43 infants) examined accuracy of telemedicine for detection of prethreshold or worse ROP, and reported sensitivity of 1.00 and specificity of $0.98 .{ }^{76}$ Similarly, Chiang et al. (2006; 163 
exams from 64 infants) examined accuracy for detection of type- 2 or worse ROP by 3 image graders, and found sensitivity ranging from $0.72-0.83$ and specificity ranging from $0.90-0.99 .{ }^{13}$ For detection of treatment-requiring ROP (defined as type- 1 or worse disease), the same study found sensitivity of $0.85-0.90$ and specificity of $0.95-0.97 .{ }^{13}$ In the final study, Chiang et al. (2007; 248 exams from 68 infants), prospectively examined performance by three pediatric retinal specialist graders for detection of type-2 or worse ROP. At 31-33 weeks PMA, sensitivity was $0.71-0.86$ and specificity was $0.93-0.97 .{ }^{15}$ At $35-37$ weeks PMA, sensitivity was $1.00-1.00$ and specificity was $0.85-0.94 .{ }^{15}$

Two studies have assessed diagnostic performance by analyzing the development of moderate to severe ROP over multiple longitudinal examinations (Table 3). These studies consisted of paired serial exams by ophthalmoscopy and telemedicine, and determined whether telemedicine could detect the presence of moderate to severe ROP at any point during the cumulative clinical course. Ells et al. (2003; 371 exams from 36 infants) examined detection of "referral-warranted ROP" (defined similarly to type- 2 or worse disease ${ }^{a}$ ) at any time during longitudinal inpatient examinations, and found sensitivity of 1.00 and specificity of $0.96 .{ }^{23}$

The prospective, multi-center Photographic Screening for ROP (Photo-ROP) study (2008; 300 exams from 51 infants) examined detection of "clinically significant ROP" (defined similarly to type-2 or worse disease, or inability to rule-out disease ${ }^{b}$ ) at any time during multiple longitudinal examinations. ${ }^{3,4}$ This study showed that "clinically significant ROP" was detected with sensitivity of 0.92 and specificity of $0.37 .{ }^{4}$

Overall, these findings suggest that the factors limiting accuracy for diagnosis of moderate to severe ROP (e.g., failure to detect plus disease) are likely to be different from those that limit the accuracy for diagnosis of any ROP (e.g., failure to detect peripheral disease).

\section{Reliability}

1. Inter-grader Reliability-Inter-grader reliability of telemedicine has been evaluated by comparing the diagnostic responses of multiple expert image graders who have evaluated the same images. One study demonstrated weighted kappa of $0.67-0.83$ for pairs of graders reviewing the same images, ${ }^{13}$ while another found weighted kappa of 0.55-0.74 among images at 31-33 weeks PMA and 0.79-0.89 at 35-37 weeks PMA. ${ }^{15}$ For comparison, the Early Treatment Diabetic Retinopathy Study (ETDRS) 7-field criterion standard demonstrated weighted kappa of 0.41-0.80 for inter-grader reliability of image-based diabetic retinopathy diagnosis, depending on the lesion type. ${ }^{21}$ In a study involving fluorescein angiogram interpretation for photodynamic therapy eligibility in age-related macular degeneration (AMD), the kappa was 0.37-0.40 for inter-grader reliability. ${ }^{34}$ While these comparisons should be taken with caution because they are made in different retinal diseases, these findings suggest that inter-grader reliability for telemedical ROP detection is comparable to or better than that of other well-accepted diagnostic tests in ophthalmology.

2. Intra-grader Reliability-Intra-grader reliability of telemedicine has been evaluated by analyzing the diagnosis of randomly-repeated images presented to the same grader. Chiang et al. demonstrated near-perfect to perfect agreement in a study involving 3 retinal specialist graders, with intra-grader kappa of 0.91-1.00 for detection of mild or worse ROP at 35-37 weeks PMA, and kappa of 0.79-1.00 for detection of treatment-requiring ROP at 35-37 weeks

\footnotetext{
a"Referral-warranted ROP" was defined was any ROP in zone 1, presence of plus disease, or presence of any stage 3 ROP at any time during infant's hospital course.

b“Clinically significant ROP" was defined as a) zone 1, any ROP, without vascular dilation or tortuosity; b) zone II, stage 2, with up to one quadrant of vascular dilation and tortuosity; c) zone II, stage 3, with up to one quadrant of vascular dilation and tortuosity; d) any vascular dilation and tortuosity noted in eyes for which ridge characteristics were not interpretable (not imaged or poor image quality); or e) any ROP noted in eyes for which disc features (plus disease) were not interpretable (not imaged or poor image quality).
} 
PMA. ${ }^{15}$ For comparison, the kappa for intra-grader reliability of fluorescein angiogram interpretation for determining photodynamic therapy eligibility in AMD has been found to be $0.44-0.89,{ }^{34}$ and the intra-grader concordance of fluorescein angiography for detection of classic choroidal neovascularization has been shown to be $0.66-1.00 .{ }^{41}$

\section{Image Quality}

Assessment of image quality is an important consideration for telemedical diagnosis of ROP. Wu et al. reported that $21 \%$ of initial retinal images and $22 \%$ of repeated images were considered unacceptable for diagnosis by graders. ${ }^{76}$ The Photo-ROP cooperative group found that $8 \%$ of image sets were uninterpretable. ${ }^{4}$ Chiang et al. (2007) showed that 3 telemedicine graders reported an "unknown" diagnosis (due to inadequate image quality or incomplete retinal coverage) in 0-41\% of eye exams among infants at 31-33 weeks PMA, and in 0-7\% of eye exams among infants at 35-37 weeks PMA. ${ }^{15}$ Studies have observed that heavy fundus pigmentation and factors associated with younger infants, such as increased corneal and vitreous haze, and smaller palpebral fissures and pupils, could lead to decreased image quality. $15,76,77$

\section{E. Examination vs. Screening}

In principle, telemedicine could either be used to perform ROP "examination" by reporting comprehensive retinal findings, or to perform "screening" by identifying infants with sufficiently severe disease to require referral for full examination. ${ }^{71}$ Some of the above telemedicine studies have evaluated the efficacy of using multiple wide-angle images from an "examination" perspective (Table 1), whereas others have evaluated performance of "screening"-type functions such as detection of moderate or worse ROP requiring referral (Tables 2 and 3). It is not clear whether the ultimate role of real-world telemedicine systems should be to substitute for full examinations, or whether it should be to screen for the subset of infants with disease requiring evaluation by experts.

Two telemedicine studies have explored the efficacy of ROP "screening" using posterior pole images. ${ }^{46,69}$ Lajoie et al. (2008; 248 exams from 67 infants) examined the detection of moderate to severe ROP from a single wide-angle, posterior pole image by 3 experienced graders. ${ }^{46}$ For detection of type- 2 or worse ROP from single images, sensitivity was $0.69-1.00$, and specificity was $0.87-1.00$. For detection of plus disease from single images, sensitivity was $1.00-1.00$, and specificity was $0.79-0.95 .{ }^{46}$ Skalet et al. (2008; 110 exams from 28 infants) conducted a feasibility study involving capture of three images from each eye (1 posterior and 2 peripheral) by a narrow-angle retinal camera (Nidek NM200-D; Hiroishi, Japan) for detection of "referral-warranted ROP" captured at the NICU bedside by nurses in Peru, and interpreted by 5 experienced graders. Images were successfully captured in 56/58 (97\%) sessions, and preliminary studies showed that sensitivity was $0.46-0.95$ and specificity was $0.62-0.96$ for detection of "referral-warranted ROP". ${ }^{9}$ Taken together, these pilot studies raise the possibility that retinal imaging might eventually be used to support single-image telemedical screening for moderate to severe ROP. This may be applicable in areas with limited access to resources for ROP care.

\section{F. Cost-Effectiveness}

The long-term viability of a telemedicine program for ROP will also depend on economic factors. Two studies, one from the U.S. and another from the U.K., have directly compared the cost-effectiveness of telemedicine versus ophthalmoscopy for ROP management. ${ }^{7,37}$ Both

\footnotetext{
c“Referral-warranted ROP" was defined as any ROP in zone 1, presence of plus disease, or presence of any stage 3 ROP at any time during infant's hospital course.
} 
studies assumed the diagnostic accuracy of telemedicine and ophthalmoscopy to be identical, based on the notion that previous research does not suggest one modality to systematically outperform the other. These studies were similar in that they created decision tree models based on published research involving ROP epidemiology and treatment efficacy. Both analyses found that several telemedicine strategies were more cost-effective than current ophthalmoscopic management strategies.

The U.S. study modeled two scenarios: (1) standard examinations by an experienced ophthalmologist, and (2) telemedicine examinations by non-ophthalmic personnel using wideangle imaging devices. It was conducted from a third-party payer perspective using 2006 Medicare costs for ophthalmoscopic and photographic examinations, and did not consider nonreimbursed costs such as equipment and training. Accuracy of telemedical diagnosis, as well

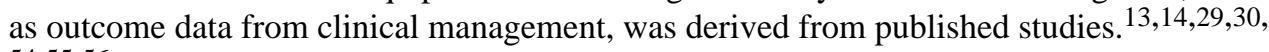
$54,55,56$ This showed that telemedicine for ROP management costs $\$ 3193$ per quality-adjusted life year (QALY) gained, whereas traditional management involving serial ophthalmoscopy costs $\$ 5617$ per QALY gained. ${ }^{37}$ Sensitivity analysis also showed that telemedicine had greater cost-effectiveness than ophthalmoscopy over a range of parameter values including accuracies of telemedicine and ophthalmoscopy, incidence of treatment-requiring ROP, and percentage of telemedicine images that were readable.

The U.K. study modeled five potential strategies for ROP surveillance: (1) telemedicine with both image capture and grading by visiting nurses, (2) telemedicine with image captured by visiting nurses and image grading by remote ophthalmologists, (3) telemedicine with both image capture and grading by neonatal nurses, (4) telemedicine with image capture by neonatal nurses and image grading by remote ophthalmologists, and (5) traditional serial bedside ophthalmoscopy by an ophthalmologist. This study was conducted from a single-party payer perspective, and clinical outcome data were derived from published studies. ${ }^{29,30,40,54,55,56}$ Compared to traditional bedside ophthalmoscopy (£321 per infant examined), this study found that telemedicine with both image capture and grading by visiting nurses ( $£ 172$ per infant examined) and telemedicine with image capture by visiting nurses and image grading by remote ophthalmologists (£201 per infant examined) would be the most cost-effective strategies. ${ }^{7}$ While using trained nurses to capture adequate-quality retinal images has been shown to be effective, ${ }^{15,53,63,68,77}$ the accuracy of trained nurses for image grading must be examined with additional research.

To anticipate the impact of a telemedicine program for ROP, it may also be necessary to consider societal costs and benefits that are more difficult to quantify. For example, telemedicine may offer benefits for ophthalmologists such as time-savings, subjectively greater provider satisfaction, and availability of retinal images for secondary purposes such as education, research, and quality improvement. Telemedicine might lead to either decreased risk for medico-legal liability because of improved documentation of examination findings, or to increased risk due to wider availability of objective imaging data for scrutiny. Finally, telemedicine might cause dissatisfaction for some families who prefer the possibility of faceto-face discussion with an ophthalmologist. These factors may require further study.

\section{Challenges}

\section{A. What is the true gold standard?}

In all of the above studies, accuracy of telemedical ROP diagnosis was compared to a reference standard of dilated indirect ophthalmoscopy by an experienced examiner. Yet it is not clear that this represents a true gold standard. For instance, ophthalmoscopy might inadvertently lead to inadequate assessments due to infant movements and small pupils, and paper-based documentation of retinal findings from indirect ophthalmoscopy is also less objective and 
subject to observer variation. ${ }^{71}$ An epidemiological study in Australia and New Zealand suggested that the varying rates of ROP incidence across geographical regions may result from observer bias. ${ }^{19,20}$ A clinical study to directly examine the accuracy of serial indirect ophthalmoscopy by multiple examiners on the same infants has never been conducted, and might be impractical because of concerns about infant safety. ${ }^{51}$

Scott et al. performed a study that controlled for inter-physician variability by examining ophthalmoscopic and telemedical examinations of 67 infants by the same graders. There was substantial to near-perfect agreement in these diagnostic modalities, with absolute agreement of $86 \%$ (178/206 eyes) and kappa of $0.66-0.85$ between ophthalmoscopy and telemedicine. ${ }^{63}$ Among the $14 \%$ (28/206 eyes) discrepancies in this study, some cases provided photographic documentation suggesting that ophthalmoscopic examination may have missed signs of mild ROP. In addition, there were several discrepancies between presence of zone-1 ROP and presence of plus disease, in which telemedicine may have provided the theoretical advantages of allowing examiners to review their diagnoses, make more exact measurements of anatomical landmarks defining zone 1 of the retina, and directly compare images to the standard photograph for plus disease. ${ }^{63}$

Ells et al. suggested that telemedicine may detect moderate to severe ROP before ophthalmoscopy. This was based on their finding that "referral-warranted ROP" was diagnosed earlier by telemedicine than ophthalmoscopy in $43 \%$ (10/23) eyes, whereas it was diagnosed earlier by ophthalmoscopy than telemedicine in only $13 \%(2 / 23)$ eyes. ${ }^{23}$

Overall, research has suggested that there may be non-trivial variability in ROP diagnosis, even among experts. ${ }^{11,58,73}$ During ophthalmoscopic examinations in the CRYO-ROP trial, $12 \%$ of eyes diagnosed with threshold disease by one study-certified expert were diagnosed with less-than-threshold disease by a second certified expert who was asked to perform a confirmatory examination. ${ }^{58}$ The second examiner was unmasked to the fact that the first examiner had diagnosed threshold ROP, and this level of disagreement may have been even higher in the setting of a fully masked study design. A study of image-based plus disease detection found that 22 experts agreed on the same diagnosis (plus vs. not plus) in only $21 \%$ (7/34) of images, and that the mean kappa for each expert compared to all others was $0.19-0.66 .{ }^{11}$ Compared to a reference standard defined as the diagnosis selected by a majority of experts, the sensitivity of those 22 experts for plus disease diagnosis ranged from 0.31-1.00 and the specificity ranged from $0.57-1.00 .{ }^{25}$ Limitations in reliability may be caused by differing interpretations regarding the level of dilation and tortuosity sufficient for plus disease. Widespread retinal imaging, with subsequent development of image libraries and computerbased tools for diagnosis of plus disease based on quantitative vessel properties, may result in improved consistency. ${ }^{10,25,38,39,42,73,75}$

\section{B. Safety and Technical Considerations in Retinal Imaging}

The physiologic stress caused to premature infants by indirect ophthalmoscopy are wellknown. $6,45,47,60,61,70$ Several studies have examined the relative safety of wide-angle retinal imaging using contact retinal cameras. In a pilot study comparing the systemic effects of 3 methods (imaging with the RetCam-120, indirect ophthalmoscopy with scleral depression, and indirect ophthalmoscopy without scleral depression), Mehta et al. reported a greater stress response when retinal imaging or scleral depression were employed. ${ }^{51}$ A larger study by Mukherjee et al. compared infant stress response during RetCam-120 imaging to the response during indirect ophthalmoscopy with scleral depression. This showed that both modalities were stressful to infants, but that imaging was significantly less stressful even though it required approximately twice as much time. ${ }^{52}$ 
With regard to ocular complications, there has been one reported case of retinal hemorrhages following RetCam imaging and ophthalmoscopy with scleral depression. ${ }^{1}$ A follow-up investigation which involved performing indirect ophthalmoscopy 1 hour after ROP RetCam imaging in 50 eyes of 25 premature infants reported no retinal hemorrhages. ${ }^{2}$ Some papers involving telemedical ROP diagnosis have specifically reported no cases of ocular or systemic complications following contact retinal imaging. ${ }^{15,77}$ Although no ocular complications have been reported in other telemedicine studies, safety was not an explicit outcome measure in those other studies.

In addition, there are technical considerations in retinal imaging. Some investigators have raised concerns that imaging the retinal periphery using the RetCam-120 device (Clarity Medical Systems; Pleasanton, CA) was difficult, particularly in small infants with narrow palpebral fissures. ${ }^{13,59,77}$ Newer camera lenses may have improved this problem, ${ }^{23,53}$ and others have argued that imaging of mild peripheral ROP disease is less clinically-important. 12,53,68,72 The RetCam contact camera offers several lenses with different fields of view, and other non-contact devices are available with narrower fields of view (e.g., Nidek NM200-D, Hiroishi, Japan). The tradeoffs associated with these devices may warrant further research, particularly because image magnification may affect plus disease diagnosis. ${ }^{11}$

A final technical concern relates to the training and expertise of both camera operators and image graders. Telemedicine studies with trained non-ophthalmologist camera operators have had high accuracy, ${ }^{15,63}$ comparable to accuracy in studies using ophthalmologist camera operators. However, specific training protocols emphasizing important technical considerations during image capture may be important. For example, contact cameras have potential to alter the appearance of retinal vessels. One case report cited variation in the appearance of peripheral ROP that was attributed to excessive force from the camera lens. ${ }^{43}$ Image graders may also benefit from specific training protocols. Compared to indirect ophthalmoscopy, RetCam images are wider-angle and lacking in stereo view. To adapt for such differences, some have suggested the possibility of training graders using real-time imaging videos. $^{49}$

\section{Unresolved Issues}

Several key issues involving telemedical ROP diagnosis remain unresolved. It is not clear what constitutes "adequate" accuracy for implementation of real-world systems, particularly given that the accuracy of ophthalmoscopic examinations is not known. A reasonable diagnostic cutoff might be to refer all infants who are felt by telemedicine graders to have type- 2 or worse ROP, although cost-benefit tradeoffs must be examined.$^{37}$ Low sensitivity may result in missed cases of disease, whereas low specificity may result in unnecessary over-referrals. From this perspective, the societal impacts of missed ROP cases contributing to avoidable childhood blindness versus the inefficient use of limited ophthalmology resources must be examined. Also, a high proportion of unreadable images in a telemedicine program could pose significant challenges, because these infants would require either repeat imaging or referral for ophthalmoscopic exam. ${ }^{15,76}$ "Aggressive-posterior ROP,"36 which requires timely detection and treatment, may present at earlier PMA when image quality has been shown to be lower. The role of telemedicine as a tool for "examination" vs. "screening" must also be clearly defined, with protocols specifying the appropriate number of images, criteria for referral, and type of camera in various settings.

Ultimately, the feasibility of telemedicine for ROP will depend largely on resolution of logistical challenges such as integration into existing neonatology workflow, reimbursement, licensure, development of standard protocols for retinal image capture, creation of training protocols for photographers and graders, and malpractice liability. For example, retinal imaging could protect physicians through improved documentation, but could also increase 
medico-legal risk by subjecting images to heavy scrutiny. These issues must be addressed before creation of a large-scale telemedicine infrastructure for ROP.

\section{Conclusions and Future Directions}

Validation studies of telemedicine for ROP diagnosis have demonstrated that its accuracy, inter-grader reliability, and intra-grader reliability are high, and are comparable or better than that of other widely-accepted diagnostic tests. This is particularly true for detection of moderate-to-severe levels of ROP, and for examination of infants at later post-menstrual ages. Accuracy and reliability of telemedical imaging at earlier post-menstrual ages are less wellestablished in the published literature.

Based on these findings, several pilot telemedicine programs have been implemented in the United States and internationally, using trained non-expert personnel to capture images and transfer data to remote ophthalmologists (Virtual Medical Worlds Monthly. Bavarian telemedicine network to screen premature babies at risk of developing blindness. http://www.hoise.com/vmw/01/articles/vmw/LV-VM-02-01-27.html. Accessed November 1, 2007) ${ }^{53,68}$ In the longer-term, expansion of these programs will require addressing many of the unresolved issues above. This may allow the ophthalmology expertise necessary for ROP management to be utilized more efficiently, delivered more accessibly to the growing population of premature infants, and explored further for application to other ophthalmic and medical disorders.

\section{Methods of Literature Search}

The Medline database was queried from January 1980 to September 2008 without date limitations. The following search terms were used: retinopathy of prematurity AND telemedicine, retinopathy of prematurity AND diagnosis, retinopathy of prematurity AND retcam imaging, retinopathy of prematurity AND retinal imaging, retinopathy of prematurity AND digital imaging, retinopathy of prematurity AND incidence, retinopathy of prematurity AND cost-effectiveness AND screening. Criteria for inclusion included the relevance, clinical importance, and scientific importance of articles to the subject of this paper. Articles cited in the reference lists of other articles were reviewed and included when considered appropriate. All articles with English abstracts were reviewed, but only English-language articles were used for this paper. Additional sources included "popular," non-peer-reviewed media regarding current telemedicine applications and ophthalmologists' attitudes, and these are cited in the text rather than included in the references section.

\section{Acknowledgments}

Funding support: MFC is supported by a Career Development Award from Research to Prevent Blindness (New York, NY) and by grant EY13972 from the National Institutes of Health (Bethesda, MD).

Disclosure: MFC is an unpaid member of the Scientific Advisory Board for Clarity Medical Systems (Pleasanton, CA).

\section{References}

1. Adams GG, Clark BJ, Fang S, Hill M. Retinal haemorrhages in an infant following retcam screening for retinopathy of prematurity. Eye 2004;18(6):652-3. [PubMed: 14716332]

2. Azad RV, Chandra P, Pal N, Singh DV. Retinal haemorrhages following retcam screening for retinopathy of prematurity. Eye 2005;19(11):1221. [PubMed: 15467695]author reply 1221-2 
3. Balasubramanian M, Capone A, Hartnett ME, et al. The photographic screening for retinopathy of prematurity study (Photo-ROP): study design and baseline characteristics of enrolled patients. Retina 2006;26(7 Suppl):S4-10. [PubMed: 16946677]

4. Balasubramanian M, Capone A, Hartnett ME, et al. The photographic screening for retinopathy of prematurity study (Photo-ROP): Primary Outcomes. Retina 2008;28(3):S47-S54. [PubMed: 18317345]

5. Bashshur RL, Reardon TG, Shannon GW. Telemedicine: a new health care delivery system. Annu Rev Public Health 2000;21:613-37. [PubMed: 10884967]

6. Belda S, Pallas CR, De la Cruz J, Tejada P. Screening for retinopathy: is it painful? Biol Neonate 2004;86(3):195-200. [PubMed: 15240989]

7. Castillo-Riquelme MC, Lord J, Moseley MJ, et al. Cost-effectiveness of digital photographic screening for retinopathy of prematurity in the United Kingdom. Int J Technol Assess Health Care 2004;20(2): 201-13. [PubMed: 15209180]

8. Chen Y, Li X. Characteristics of severe retinopathy of prematurity patients in China: a repeat of the first epidemic? Br J Ophthalmol 2006;90(3):268-71. [PubMed: 16488941]

9. Chen Y, Li X, Yin H, et al. Risk factors for retinopathy of prematurity in six neonatal intensive care units in Beijing, China. Br J Ophthalmol 2008;92(3):326-30. [PubMed: 18303154]

10. Chiang MF, Gelman R, Williams SL, et al. Plus Disease in Retinopathy of Prematurity: Development of Composite Images by Quantification of Expert Opinion. Invest Ophthalmol Vis Sci 2008;49(9): 4064-70. [PubMed: 18408188]

11. Chiang MF, Jiang L, Gelman R, et al. Interexpert agreement of plus disease diagnosis in retinopathy of prematurity. Arch Ophthalmol 2007;125(7):875-80. [PubMed: 17620564]

12. Chiang MF, Keenan JD, Du YE, et al. Assessment of image-based technology: impact of referral cutoff on accuracy and reliability of remote retinopathy of prematurity diagnosis. AMIA Annu Symp Proc 2005:126-30. [PubMed: 16779015]

13. Chiang MF, Keenan JD, Starren J, et al. Accuracy and reliability of remote retinopathy of prematurity diagnosis. Arch Ophthalmol 2006;124(3):322-7. [PubMed: 16534051]

14. Chiang MF, Starren J, Du YE, Keenan JD, Schiff WM, Barile GR, Li J, Johnson RA, Hess DJ, Flynn JT. Remote image based retinopathy of prematurity diagnosis: a receiver operating characteristic analysis of accuracy. Br J Ophthalmol 2006;90(10):1292-6. [PubMed: 16613919]

15. Chiang MF, Wang L, Busuioc M, et al. Telemedical retinopathy of prematurity diagnosis: accuracy, reliability, and image quality. Arch Ophthalmol 2007;125(11):1531-8. [PubMed: 17998515]

16. Cockey CD. Premature births hit record high. AWHONN Lifelines 2005;9(5):365-70. [PubMed: 16359074]

17. Committee for the Classification of Retinopathy of Prematurity. An international classification of retinopathy of prematurity. Arch Ophthalmol 1984;102:1130-4. [PubMed: 6547831]

18. Cryotherapy for Retinopathy of Prematurity Cooperative Group. Multicenter trial of cryotherapy for retinopathy of prematurity: preliminary results. Arch Ophthalmol 1988;106(4):471-9. [PubMed: 2895630]

19. Darlow BA, Elder MJ, Horwood LJ, et al. Does observer bias contribute to variations in the rate of retinopathy of prematurity between centres? Clin Experiment Ophthalmol 2008;36(1):43-6. [PubMed: 18290953]

20. Darlow BA, Hutchinson JL, Simpson JM, et al. Variation in rates of severe retinopathy of prematurity among neonatal intensive care units in the Australian and New Zealand Neonatal Network. Br J Ophthalmol 2005;89(12):1592-6. [PubMed: 16299138]

21. Early Treatment Diabetic Retinopathy Study Research Group. Grading diabetic retinopathy from stereoscopic color fundus photographs--an extension of the modified Airlie House classification. Ophthalmology 1991;98(5 Suppl):786-806. [PubMed: 2062513]ETDRS report number 10

22. Early Treatment for Retinopathy of Prematurity Cooperative Group. Revised indications for the treatment of retinopathy of prematurity: results of the early treatment for retinopathy of prematurity randomized trial. Arch Ophthalmol 2003;121(12):1684-94. [PubMed: 14662586]

23. Ells AL, Holmes JM, Astle WF, et al. Telemedicine approach to screening for severe retinopathy of prematurity: a pilot study. Ophthalmology 2003;110(11):2113-7. [PubMed: 14597517] 
24. Field MJ. Telemedicine: a guide to assessing telecommunications in healthcare. J Digit Imaging 1997;10(3 Suppl 1):28. [PubMed: 9268830]

25. Gelman R, Jiang L, Du YE, et al. Plus disease in retinopathy of prematurity: pilot study of computerbased and expert diagnosis. J AAPOS 2007;11(6):532-40. [PubMed: 18029210]

26. Gilbert C. Retinopathy of prematurity: a global perspective of the epidemics, population of babies at risk and implications for control. Early Hum Dev 2008;84(2):77-82. [PubMed: 18234457]

27. Gilbert C, Fielder A, Gordillo L, et al. Characteristics of infants with severe retinopathy of prematurity in countries with low, moderate, and high levels of development: implications for screening programs. Pediatrics 2005;115(5):e518-525. [PubMed: 15805336]

28. Gilbert C, Rahi J, Eckstein M, et al. Retinopathy of prematurity in middle-income countries. Lancet 1997;350(9070):12-4. [PubMed: 9217713]

29. Good WV. Final results of the early treatment for retinopathy of prematurity (ETROP) randomized trial. Trans Am Ophthalmol Soc 2004;102:233-48. [PubMed: 15747762]

30. Good WV, Hardy RJ, Dobson V, et al. Early Treatment for Retinopathy of Prematurity Cooperative Group. The incidence and course of retinopathy of prematurity: findings from the early treatment for retinopathy of prematurity study. Pediatrics 2005;116(1):15-23. [PubMed: 15995025]

31. Grabska J, Walden P, Lerer T, et al. Can oral sucrose reduce the pain and distress associated with screening for retinopathy of prematurity? J Perinatol 2005;25(1):33-5. [PubMed: 15343351]

32. Grigsby J, Sanders JH. Telemedicine: where it is and where it's going. Ann Intern Med 1998;129(2): 123-7. [PubMed: 9669971]

33. Hamilton BE, Martin JA, Ventura SJ. Births: preliminary data for 2005. Natl Vital Stat 2006;55(11): $1-18$.

34. Holz FG, Jorzik J, Schutt F, et al. Agreement among ophthalmologists in evaluating fluorescein angiograms in patients with neovascular age-related macular degeneration for photodynamic therapy eligibility (FLAP-study). Ophthalmology 2003;110(2):400-5. [PubMed: 12578787]

35. Hussein MA, Coats DK, Paysse EA. Use of the retcam 120 for fundus evaluation in uncooperative children. Am J Ophthalmol 2004;137(2):354-5. [PubMed: 14962432]

36. International Committee for the Classification of Retinopathy of Prematurity. The International Classification of Retinopathy of Prematurity revisited. Arch Ophthalmol 2005;123(7):991-9. [PubMed: 16009843]

37. Jackson KM, Scott KE, Graff-Zivin J, et al. Cost-utility analysis of telemedicine and ophthalmoscopy for retinopathy of prematurity management. Arch Ophthalmol 2008;126(4):493-9. [PubMed: 18413518]

38. Johnson KS, Mills MD, Karp KA, Grunwald JE. Quantitative analysis of retinal vessel diameter reduction after photocoagulation treatment for retinopathy of prematurity. Am J Ophthalmol 2007;143(6):1030-2. [PubMed: 17524769]

39. Johnson KS, Mills MD, Karp KA, Grunwald JE. Semiautomated analysis of retinal vessel diameter in retinopathy of prematurity patients with and without plus disease. Am J Ophthalmol 2007;143(4): 723-5. [PubMed: 17386296]

40. Joint Working Party of the Royal College of Paediatrics. Child Health the Royal College of Ophthalmologist. the British Association of Perinatal Medicine. A 5 years programme of research into the screening and treatment of retinopathy of prematurity in the UK. Royal College of Paediatrics and Child Health; London: 2002. p. 71

41. Kaiser RS, Berger JW, Williams GA, et al. Variability in fluorescein angiography interpretation for photodynamic therapy in age-related macular degeneration. Retina 2002;22(6):683-90. [PubMed: 12476092]

42. Koreen S, Gelman R, Martinez-Perez ME, et al. Evaluation of a computer-based system for plus disease diagnosis in retinopathy of prematurity. Ophthalmology 2007;114(12):e59-67. [PubMed: 18054630]

43. Koreen S, Lopez R, Jokl DH, et al. Variation in appearance of severe zone 1 retinopathy of prematurity during wide-angle contact photography. Arch Ophthalmol 2008;126(5):736-7. [PubMed: 18474793]

44. Krupinski E, Nypaver M, Poropatich R, et al. Telemedicine/telehealth: an international perspective. Clinical applications in telemedicine/telehealth. Telemed J E Health 2002;8(1):13-34. [PubMed: 12020403] 
45. Kumar H, Nainiwal S, Singha U, et al. Stress induced by screening for retinopathy of prematurity. J Pediatr Ophthalmol Strabismus 2002;39(6):349-50. [PubMed: 12458847]

46. Lajoie A, Koreen S, Wang L, et al. Retinopathy of prematurity management using single-image vs. multiple-image telemedicine examinations. Am J Ophthalmol 2008;146(2):298-309. [PubMed: 18547536]

47. Laws DE, Morton C, Weindling M, Clark D. Systemic effects of screening for retinopathy of prematurity. Br J Ophthalmol 1996;80(5):425-8. [PubMed: 8695564]

48. Lee TC, Lee SW, Dinkin MJ, et al. Chorioretinal scar growth after 810-nanometer laser treatment for retinoblastoma. Ophthalmology 2004;111(5):992-6. [PubMed: 15121379]

49. Mackeen L, Ells A. Dynamic documentation of the evolution of retinopathy of prematurity in video format. J AAPOS 2008;12(4):349-51. [PubMed: 18455934]

50. Martin JA, Hamilton BE, Sutton PD, et al. Births: Final data for 2005. Natl Vital Stat Rep 2007;56 (6):1-103. [PubMed: 18277471]

51. Mehta M, Adams GG, Bunce C, et al. Pilot study of the systemic effects of three different screening methods used for retinopathy of prematurity. Early Hum Dev 2005;81(4):355-60. [PubMed: 15814220]

52. Mukherjee AN, Watts P, Al-Madfai H, et al. Impact of retinopathy of prematurity screening examination on cardiorespiratory indices: a comparison of indirect ophthalmoscopy and retcam imaging. Am J Ophthalmol 2006;113(9):1547-52.

53. Murakami Y, Jain A, Silva R, et al. Stanford University Network for Diagnosis of Retinopathy of Prematurity (SUNDROP): 12-month experience with telemedicine screening. Br J Ophthalmol 2008;92(11):1456-60. [PubMed: 18703553]

54. Ng EYJ, Connolly BP, Mcnamara JA, et al. A comparison of laser photocoagulation with cryotherapy for retinopathy at 10 years, part 1: visual function and structural outcome. Ophthalmology 2002;109 (5):928-34. [PubMed: 11986099]

55. Palmer EA, Flynn JT, Hardy, et al. Cryotherapy for Retinopathy of Prematurity Cooperative Group. Incidence and early course of retinopathy of prematurity. Ophthalmology 1991;98(11):1628-40. [PubMed: 1800923]

56. Palmer EA, Hardy RJ, Dobson V, et al. 15-year outcomes following threshold retinopathy of prematurity: final results from the multicenter trial of cryotherapy for retinopathy of prematurity. Arch Ophthalmol 2005;123(3):311-8. [PubMed: 15767472]

57. Phelps DL. Retinopathy of prematurity: an estimate of vision loss in the United States--1979. Pediatrics 1981;67(6):924-5. [PubMed: 6894488]

58. Reynolds JD, Dobson V, Quinn GE, et al. Evidence-based screening criteria for retinopathy of prematurity: natural history data from the CRYO-ROP and LIGHT-ROP studies. Arch Ophthalmol 2002;120(11):1470-6. [PubMed: 12427059]

59. Roth DB, Morales D, Feuer WJ, et al. Screening for retinopathy of prematurity employing the retcam 120: sensitivity and specificity. Arch Ophthalmol 2001;119(2):268-72. [PubMed: 11176990]

60. Rush R, Rush S, Nicolau J, Chapman K, Nagvi M. Systemic manifestations in response to mydriasis and physical examination during screening for retinopathy of prematurity. Retina 2004;24(2):2425. [PubMed: 15097885]

61. Rush R, Rush S, Ighani F, et al. The effects of comfort care on the pain response in preterm infants undergoing screening for retinopathy of prematurity. Retina 2005;25(1):59-62. [PubMed: 15655442]

62. Schwartz SD, Harrison SA, Ferrone PJ, Trese MT. Telemedical evaluation and management of retinopathy of prematurity using a fiberoptic digital fundus camera. Ophthalmology 2000;107(1): 25-8. [PubMed: 10647714]

63. Scott KE, Kim DY, Wang L, et al. Telemedical diagnosis of retinopathy of prematurity intraphysician agreement between ophthalmoscopic examination and image-based interpretation. Ophthalmology 2008;115(7):1222-8. [PubMed: 18456337]

64. American Academy of Pediatrics; American Academy of Ophthalmology; American Association for Pediatric Ophthalmology and Strabismus. Screening examination of premature infants for retinopathy of prematurity. Pediatrics 2001;108(3):809-11. [PubMed: 11533356]Section on Ophthalmology 
65. American Academy of Pediatrics; American Academy of Ophthalmology; American Association for Pediatric Ophthalmology and Strabismus. Screening examination of premature infants for retinopathy of prematurity. Pediatrics 2006;117(2):572-6. [PubMed: 16452383]Section on Ophthalmology

66. Shah PK, Narendran V, Saravanan VR, et al. Screening for retinopathy of prematurity--a comparison between binocular indirect ophthalmoscopy and retcam 120. Indian J Ophthalmol 2006;54(1):35-8. [PubMed: 16531668]

67. Shennan AH, Bewley S. Why should preterm births be rising? BMJ 2006;332(7547):924-5. [PubMed: 16627490]

68. Silva RA, Murakami Y, Jain A, et al. Stanford University Network for Diagnosis of Retinopathy of Prematurity (SUNDROP): 18-month experience with telemedicine screening. Graefes Arch Clin Exp Ophthalmol 2009;247(1):129-36. [PubMed: 18784936]

69. Skalet AH, Quinn GE, Ying GS, et al. Telemedicine screening for retinopathy of prematurity in developing countries using digital retinal images: a feasibility project. J AAPOS 2008;12(3):252-8. [PubMed: 18289897]

70. Slevin M, Murphy JF, Daly L, O'Keefe M. Retinopathy of prematurity screening, stress-related responses, the role of nesting. Br J Ophthalmol 1997;81(9):762-4. [PubMed: 9422929]

71. Trese MT. What is the real gold standard for ROP screening? Retina 2008;28(3):S1-2. [PubMed: 18317337]

72. Vinekar A, Dogra MR, Sangtam T, et al. Retinopathy of prematurity in Asian Indian babies weighing greater than 1250 grams at birth: ten year data from a tertiary care center in a developing country. Indian J Ophthalmol 2007;55(5):331-6. [PubMed: 17699940]

73. Wallace DK, Freedman SF, Zhao Z, Jung SH. Accuracy of ROPtool vs individual examiners in assessing retinal vascular tortuosity. Arch Ophthalmol 2007a;125(11):1523-30. [PubMed: 17998514]

74. Wallace DK, Quinn GE, Freedman SF, Chiang MF. Agreement among pediatric ophthalmologists in diagnosing plus and pre-plus disease in retinopathy of prematurity. J AAPOS 2008;12(4):352-6. [PubMed: 18329925]

75. Wallace DK, Zhao Z, Freedman SF. A pilot study using "ROPtool" to quantify plus disease in retinopathy of prematurity. J AAPOS 2007b;11(4):381-7. [PubMed: 17532238]

76. Wu C, Petersen RA, VanderVeen DK. Retcam imaging for retinopathy of prematurity screening. J AAPOS 2006;10(2):107-11. [PubMed: 16678743]

77. Yen KG, Hess D, Burke B, et al. Telephotoscreening to detect retinopathy of prematurity: preliminary study of the optimum time to employ digital fundus camera imaging to detect ROP. J AAPOS 2002;6 (2):64-70. [PubMed: 11997800] 
A.

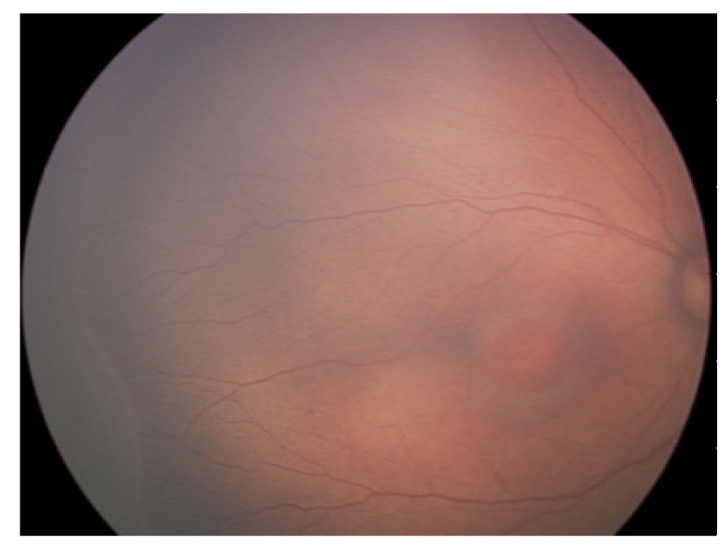

C.

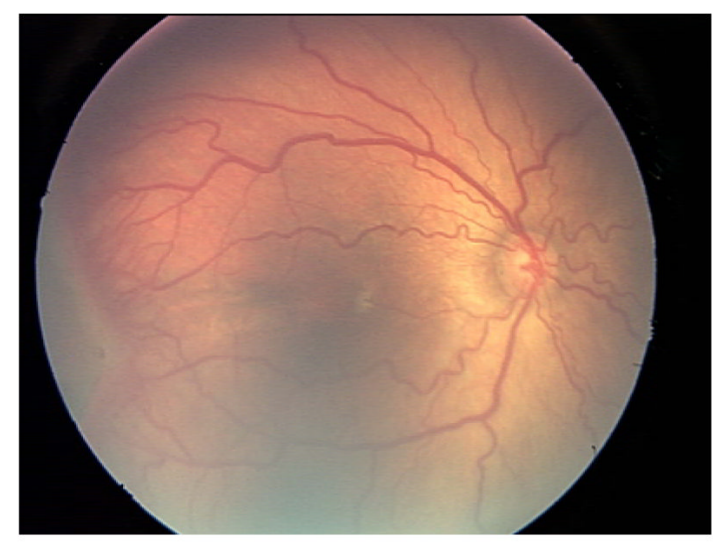

Figure. Examples of wide-angle retinal images captured with RetCam (Clarity Medical Systems, Pleasanton, $\mathrm{CA}$ ) by a trained neonatal nurse during routine ROP screening Images demonstrate (A) Mild ROP, (B) Type-2 prethreshold ROP, and (C) Treatmentrequiring ROP. 
Table 1

Summary of reported sensitivities and specificities of telemedicine for detection of any ROP, as compared to reference standard of indirect ophthalmoscopy

\section{Study \\ \# infants, \# exams \\ (proportion of}

exams with ROP
a. camera and \# images per eye
b. camera operator
c. image grader
d. clinical data provided to
graders; uni- or bilateral graders; uni- or bilater
presentation of eyes
e. study design and population

Outcome Measure

Sensitivity

Specificity

\begin{tabular}{|c|c|c|c|c|c|}
\hline \multirow{5}{*}{$\begin{array}{l}\text { Roth et al. }(2001) \\
32 \text { infants, } 100 \\
\text { exams } \\
(68 \% \text { exams with } \\
\text { ROP })\end{array}$} & a. & RetCam-120; $1-6$ images per eye & \multirow[t]{5}{*}{ any ROP } & \multirow[t]{5}{*}{0.82} & \multirow[t]{5}{*}{0.94} \\
\hline & b. & $\begin{array}{l}\text { nurse or ophthalmic } \\
\text { photographer }\end{array}$ & & & \\
\hline & c. & $\begin{array}{l}\text { consensus of } 1 \text { pediatric } \\
\text { ophthalmologist and } 1 \\
\text { ophthalmology resident }\end{array}$ & & & \\
\hline & d. & none; unilateral & & & \\
\hline & e. & $\begin{array}{l}\text { consecutive enrollment of } \\
\text { screening population (Miami, } \\
\text { Florida) }\end{array}$ & & & \\
\hline \multirow{5}{*}{$\begin{array}{l}\text { Yen et al. (2002) } \\
25 \text { infants, } 96 \\
\text { exams } \\
(55 \% \text { exams with } \\
\text { ROP })\end{array}$} & a. & RetCam-120; 4-8 images per eye & \multirow{5}{*}{$\begin{array}{l}\text { any ROP at } 32-34 \text { wks } \\
\text { PMA }^{+} \\
\text {any ROP at } 38-40 \text { wks } \\
\text { PMA }^{+}\end{array}$} & \multirow{5}{*}{$\begin{array}{l}0.46 \\
0.76\end{array}$} & \multirow{5}{*}{$\begin{array}{l}1.00 \\
1.00\end{array}$} \\
\hline & b. & nurse & & & \\
\hline & c. & $\begin{array}{l}\text { consensus of } 1 \text { pediatric } \\
\text { ophthalmologist and } 1 \text { pediatric } \\
\text { ophthalmologist fellow }\end{array}$ & & & \\
\hline & d. & none; unilateral (few bilateral) & & & \\
\hline & e. & $\begin{array}{l}\text { consecutive enrollment of } \\
\text { screening population (Miami, } \\
\text { Florida) }\end{array}$ & & & \\
\hline \multirow{5}{*}{$\begin{array}{l}\text { Shah et al (2006) } \\
27 \text { infants, } 87 \\
\text { exams } \\
(72 \% \text { exams with } \\
\text { ROP })\end{array}$} & a. & RetCam-120; 4-5 images per eye & \multirow[t]{5}{*}{ any ROP } & \multirow[t]{5}{*}{0.86} & \multirow[t]{5}{*}{0.92} \\
\hline & b. & vitreoretinal specialist & & & \\
\hline & c. & 1 vitreoretinal specialist & & & \\
\hline & d. & none; unilateral & & & \\
\hline & e. & $\begin{array}{l}\text { consecutive enrollment of } \\
\text { screening population (India) }\end{array}$ & & & \\
\hline \multirow{5}{*}{$\begin{array}{l}\text { Chiang et al. } \\
(2006) \\
64 \text { infants, } 163 \\
\text { exams } \\
(61 \% \text { exams with } \\
\text { ROP) }\end{array}$} & a. & RetCam-120; 1-7 images/eye & \multirow[t]{5}{*}{ any ROP } & \multirow[t]{5}{*}{$0.82-0.86$} & \multirow[t]{5}{*}{$0.49-0.96$} \\
\hline & b. & ophthalmic photographer & & & \\
\hline & c. & $\begin{array}{l}2 \text { retinal specialists and } 1 \text { general } \\
\text { ophthalmologist with limited } \\
\text { ROP experience }\end{array}$ & & & \\
\hline & d. & none; unilateral & & & \\
\hline & e. & $\begin{array}{l}\text { consecutive enrollment of } \\
\text { screening population (Miami, } \\
\text { Florida) }\end{array}$ & & & \\
\hline \multirow{3}{*}{$\begin{array}{l}\text { Chiang et al. } \\
(2007) \\
68 \text { infants, } 248 \\
\text { exams } \\
(50 \% \text { exams with } \\
\text { ROP })\end{array}$} & a. & RetCam-II; 3-5 images/eye & \multirow{3}{*}{$\begin{array}{l}\text { any ROP at } 31-33 \text { wks } \\
\text { PMA }^{\ddagger} \\
\text { any ROP at } 35-37 \text { wks } \\
\text { PMA }^{\ddagger}\end{array}$} & \multirow{3}{*}{$\begin{array}{l}0.73-0.94 \\
0.91-0.97\end{array}$} & \multirow{3}{*}{$\begin{array}{l}0.89-0.97 \\
0.98-1.00\end{array}$} \\
\hline & b. & nurse & & & \\
\hline & c. & $\begin{array}{l}3 \text { retinal specialists experienced } \\
\text { in ROP }\end{array}$ & & & \\
\hline
\end{tabular}




\begin{tabular}{|c|c|c|c|c|c|}
\hline \multirow[t]{2}{*}{$\begin{array}{l}\text { Study } \\
\text { \# infants, \# exams } \\
\text { (proportion of } \\
\text { exams with ROP) }\end{array}$} & $\begin{array}{l}\text { a. } \\
\text { b. } \\
\text { c. } \\
\text { d. } \\
\text { e. }\end{array}$ & $\begin{array}{l}\text { camera and \# images per eye } \\
\text { camera operator } \\
\text { image grader } \\
\text { clinical data provided to } \\
\text { graders; uni- or bilateral } \\
\text { presentation of eyes } \\
\text { study design and population }\end{array}$ & Outcome Measure & Sensitivity & Specificity \\
\hline & d. & $\begin{array}{l}\mathrm{BW}^{*}, \mathrm{GA} \dagger, \mathrm{PMA}^{\dagger} ; \text { bilateral } \\
\text { consecutive enrollment of } \\
\text { screening population (New } \\
\text { York, New York) }\end{array}$ & & & \\
\hline \multicolumn{6}{|l|}{ * BW, birth weight } \\
\hline${ }^{\dagger} \mathrm{GA}$, gestational age & & & & & \\
\hline
\end{tabular}


Table 2

Summary of reported sensitivities and specificities of telemedicine for detection of moderate to severe ROP, as compared to reference standard of indirect ophthalmoscopy

\begin{tabular}{lll}
\hline $\begin{array}{l}\text { Study } \\
\text { \# infants, \# eye } \\
\text { exams } \\
\text { (proportion of } \\
\text { exams with } \text { ROP) }\end{array}$ & a. & camera and \# images per eye \\
& b. & camera operator \\
& c. & image grader \\
d. & $\begin{array}{l}\text { clinical data provided to } \\
\text { graders; unilateral or } \\
\text { bilateral presentation of eyes }\end{array}$ \\
& e. & study design and population
\end{tabular}

Schwartz et al.

(2000)

10 infants, 19

exams

(100\% exams

with $R O P$ ) *

\section{Chiang et al.}

(2006)

64 infants, 163

exams

(61\% exams with

ROP

\begin{abstract}
Wu et al. (2006)
43 infants, 86

exams

$(42 \%$ infants with

$\mathrm{ROP}$ )
\end{abstract}

a. RetCam-120; 9 images per eye

b. ophthalmologist

c. 2 specialists

d. $\mathrm{BW}^{\dagger}$ and $\mathrm{PMA}^{+}$; bilateral

e. selection of 19 eyes with severe disease (Los Angeles, CA)

a. RetCam-120;1-7 images per eye

b. ophthalmic photographer

c. $\quad 2$ retinal specialists and 1 general ophthalmologist with limited ROP experience

d. none; unilateral

e. consecutive enrollment of eligible population (Miami, Florida)

a. RetCam-II; 1-5 images per eye

b. pediatric ophthalmologist or ophthalmic photographer

c. 1 pediatric ophthalmologist

d. $\mathrm{BW}^{\dagger}, \mathrm{GA} \S, \mathrm{PMA}^{\star}$, race, sex, and birth multiplicity; unknown

e. consecutive enrollment of eligible population (Boston, Massachusetts)

a. RetCam-II; 3-5 images per eye

b. nurse

c. 3 retinal specialists experienced in ROP

d. $\mathrm{BW}^{\dagger}, \mathrm{GA} \S, \mathrm{PMA}^{*} ;$ bilateral

e. consecutive enrollment of eligible population (New York, New York)
Outcome Measure

Sensitivity

Specificity

plus disease

1.00

$0(n=1)$

type- 2 or worse ROP treatment-requiring
ROP

$0.72-0.83$

$0.85-0.90$

0.90-0.99 0.95-0.97

prethreshold or worse

1.00

0.98

\section{政}


${ }^{\dagger} \mathrm{BW}$, birth weight

†PMA, post-menstrual age

$\S_{\mathrm{GA}}$, gestational age

/NA, not applicable 
Table 3

Summary of reported sensitivities and specificities of telemedicine for detection of clinically relevant ROP, as compared to reference standard of indirect ophthalmoscopy, over the infant's cumulative clinical course

\begin{tabular}{|c|c|c|c|c|c|}
\hline $\begin{array}{l}\text { Study } \\
\text { \# infants, \# eye } \\
\text { exams } \\
\text { (proportion of } \\
\text { exams with ROP) }\end{array}$ & $\begin{array}{l}\text { a. } \\
\text { b. } \\
\text { c. } \\
\text { d. } \\
\text { e. }\end{array}$ & $\begin{array}{l}\text { camera and \# images per } \\
\text { eye } \\
\text { camera operator } \\
\text { image grader } \\
\text { clinical data provided to } \\
\text { graders; unilateral or } \\
\text { bilateral presentation of } \\
\text { eyes } \\
\text { study design and } \\
\text { population }\end{array}$ & Outcome Measure & Sensitivity & Specificity \\
\hline
\end{tabular}

$$
\begin{aligned}
& \text { Ells et al. (2003) } \\
& 36 \text { infants, } 371 \\
& \text { exams } \\
& \text { (32\% eyes with } \\
& \text { "referral- } \\
& \text { warranted ROP") }
\end{aligned}
$$

Photo-ROP

Cooperative

Group (2008)

51 infants, 300

exams $(58 \%$ eyes

with "clinically

significant ROP”) a. RetCam-120; 5 images per eye

referral-warranted ROP ${ }^{*}$

1.00

0.96

b. pediatric ophthalmologist

c. pediatric ophthalmologist

d. none; unilateral

e. consecutive enrollment of eligible population (Alberta, Canada)

a. RetCam-120; 5 images per eye

Clinically-significant $\mathrm{ROP}^{\dagger}$ or worse

0.92 0.37

b. ophthalmologist

c. 2 ROP specialists, by consensus

d. none; unilateral

e. consecutive enrollment of eligible population at 6 US study centers

\footnotetext{
* Referral-warranted ROP is defined as any ROP in zone 1, presence of plus disease, or presence of any stage 3 ROP at any time during infant's hospital course.

${ }^{\dagger}$ Clinically-significant ROP defined as: a) zone 1, any ROP, without vascular dilation or tortuosity; b) zone II, stage 2, with up to one quadrant of vascular dilation and tortuosity; c) zone II, stage 3, with up to one quadrant of vascular dilation and tortuosity; d) any vascular dilation and tortuosity noted in eyes for which ridge characteristics were not interpretable (not imaged or poor image quality); or e) any ROP noted in eyes for which disc features (plus disease) were not interpretable (not imaged or poor image quality
} 